\title{
Symptoms of hand-arm vibration syndrome in gas distribution operatives
}

\author{
Keith Palmer, Granville Crane, Hazel Inskip
}

\begin{abstract}
Objectives-To survey the prevalence and severity of hand-arm vibration syndrome symptoms (HAVS), and to estimate past and current exposure to hand held vibrating tools in a sample of gas distribution operatives breaking and re-instating road surfaces.
\end{abstract}

Methods-153 gas distribution operatives (participation rate $81 \%$ ) from three company districts were assessed by an administered questionnaire, a clinical examination, and a simple cold challenge test to the hands. Exposure histories were taken aided by a picture album of past and current tools. Information was obtained from several sources on the likely vibratory characteristics of those tools. Estimates were thus obtained of the frequency of blanching and neurological complaints in operatives, and of their lifetime hours of exposure and lifetime dose of vibration.

Results-On average, the sample had spent 16 years in employment involving use of vibratory tools. $24 \%$ had symptoms or signs of blanching after use of tools in the industry; $46 \%$ had troublesome persistent complaints of paraesthesiae or numbness, and these symptoms extended into the hands or arms in $18 \%$ of workers. In $5.9 \%$ the distribution of symptoms was suggestive of carpal tunnel syndrome; and of ulnar nerve entrapment in a further $3.9 \%$. The risks of blanching and neurological complaints rose significantly with lifetime hours of use of vibrating tools and lifetime dose of vibration. Symptoms were generally mild and apparent only after a prolonged interval, but there were exceptions, and cases had occurred after lower recent exposures. Conclusions-It has been suggested that aspects of the gas distribution operative's work mitigate against the risk normally anticipated from use of pneumatic road breaking tools. By contrast our data suggest that symptoms of HAVS do occur, given sufficient exposure, a finding relevant not only to gas supply workers, but also to workers from other industries who break and repair road surfaces. (Occup Environ Med 1998;55:716-721)

Keywords: hand-arm vibration syndrome; gas supply workers

Exposure to vibration in users of pneumatic hand drills is notoriously high. Griffin, ${ }^{1}$ for example, has identified more than 80 published reports of vibration white finger (VWF) in users, and one survey found a prevalence of $80 \%$ in regularly exposed limestone quarrymen. ${ }^{2}$

Published estimates of the frequency weighted acceleration profiles of road breaking tools $^{3-7}$ imply a considerable risk of hand-arm vibration syndrome (HAVS) in regular users involved in the laying of mains supplies and cabling, construction, and road and kerbstone repair. However, a survey of white finger symptoms in gas supply workers concluded that they were no more likely than controls (gas meter readers) to experience blanching, and that VWF was "not a particular problem in the gas industry". ${ }^{78}$ The authors suggested that their findings might have arisen because of intermittent exposure, or because the tasks carried out permitted light grip of the tools, or because the risk from vibration at the lower end of the frequency spectrum - such as that generated from road breakers-was less than implied in suggested standards.

This appraisal was based on a cross sectional survey of young employees (mean age 36 years), many of whom had been exposed for $<5$ years. A different assessment of risk might have followed the examination of a more seasoned workforce, or a prospective enquiry, but this has been little studied. The occurrence of other symptoms of HAVS was not examined at the time, and such information would be helpful in a global assessment of risk.

Under statutory reporting arrangments, the United Kingdom enforcing authorites receive reports of VWF from the utility sectors, local authorities, and construction and other industries engaged in road breaking work. There is national growth in this activity but limited information on the risks involved, so the Health and Safety Executive (HSE) decided to supplement existing sources of information by conducting a further cross sectional survey of symptoms and exposure patterns in gas workers.

The gas distribution industry provides and maintains a gas supply by laying gas pipes and replacing them where necessary. For many years pneumatic hammers and drills have been used to break and reinstate road surfaces. Hydraulic versions have also been used. The task of road breaking generally rotates within a small team of two or three distribution operatives (craftsmen, distribution fitters, and their assistants). Over the past two decades, technological advances have allowed the use of "no dig" techniques. Where formerly long lengths of rolled asphalt and concrete surfaces were laid open with vibratory tools, it is now possible to thread polyethylene pipes through the bore of older pipework. This method can be used where down sizing 
(the reduction in diameter of the carrier pipe) is an acceptable cost.

No dig techniques can also be used to lay new pipe work. Since 1978 guided burrowing machines (moles) have been used to tunnel from the street supply to domestic thresholds. More recently, moles have been guided over longer distances, allowing up to 500 metres of pipe to be laid from two circumscribed holes. These service led innovations have progressively reduced exposure to hand-transmitted vibration for distribution operatives. However, the use of vibratory tools remains commonplace, even in those employed by innovative industrial leaders.

This study was conducted in a large gas supplier that had progressively introduced such improvements over the past decade. Our objectives were to determine in a sample of gas distribution operatives the prevalence and severity of symptoms arising from occupational use of hand held vibratory tools; to estimate their past and current exposure to vibration, and to formulate a suitable assessment of risk.

\section{Method}

POPULATIONS AND CLINICAL ASSESSMENTS

The study was conducted in three districts within the company in the southern half of England. With the agreement of management and union all male distribution operatives from the districts were invited to participate in the survey sessions, which were held in March 1994.

Each participant attended a clinical interview with a doctor or nurse from the Health and Safety Executive's Employment Medical Advisory Service. The interviewers had previously attended a training session aimed at improving their consistency when conducting an interview. Assessment comprised an administered questionnaire, clinical examination, and a cold challenge test applied to the hands.

The questionnaire and examination were based on the model questionnaire proposed by the Royal College of Physicians Faculty of Occupational Medicine, ${ }^{9}$ but modified to include information on distribution of symptoms (for tingling and numbness) and a detailed exposure history. Assessment included examination of the upper limb pulses and a neurological examination of the hands and upper limbs, but no electrophysiological studies were performed. In the cold challenge test both hands were immersed in cold water $\left(2-8^{\circ} \mathrm{C}\right)$ for four minutes, and then inspected for blanching (plethysmography and measurements of finger temperature and finger systolic blood pressure were not available in this field study).

In interpreting responses and clinical signs, blanching was taken to be a history of blanching, or clinical signs on cold challenge, or both. Symptoms were only classified as present if persistent, recurrent, troublesome, well demarcated, and precipitated by cold. The cold challenge test was graded as definite or probable, but only the definite findings were counted as blanching in the absence of a history of symptoms. The severity of blanching was graded on clinical history with the scale proposed by Griffin, ${ }^{10}$ with scores summed for both hands .

Neurological complaints were taken to be a history of paraesthesiae, numbness, or both. Symptoms were only classified as present if troublesome, persistent, not related to immediate use of tools, and without obvious alternative explanation; they were subclassified into those confined to the fingers, those extending beyond into the hand, wrist or arm, and those in whom distribution and pattern corresponded to a recognised nerve entrapment (carpal tunnel syndrome or ulnar nerve entrapment).

\section{ASSESSMENT OF EXPOSURE}

Before conducting the interviews, detailed information was sought on tools in current and past use. A picture album was assembled to aid tool recognition and to act as a prompt when taking histories of exposure. Also the tool manufacturers, the company, and the Health and Safety Executive's Technical and Health Sciences Division were asked to provide information on the vibration characteristics of the tools, so far as this existed.

Questionnaire responses were used to calculate, for each man, the lifetime hours of tool use for the three main tool types-compressor gun, road drill, and vibrotactile compressor (wacker) - and these were summed to provide an overall total. An attempt was made to record, so far as participants were able to estimate this, hand tool contact time rather than time taken to complete the job.

With the picture album and the other data sources, we succeeded in identifying for $82 \%$ of total hours worked, tool names for which indicative vibration exposure measurements existed. In the rest we substituted the published levels for similar tools of the era. Each respondent's exposure history was broken down into discrete time intervals over which the tools and their mean duration of daily use could be defined. For each time interval a mean daily exposure dose $\left(\mathrm{A}_{8}\right)$ was calculated by assuming the time depedency in ISO 5349 and summing the partial doses from each tool; this was converted into an interval dose by mutiplying the daily exposure dose by the duration of the period in days. Interval doses were summed to derive a lifetime dose. Thus:

$\operatorname{dose}_{n}=\left[\sum_{i}\left(a_{i}^{2} t_{i}\right)\right]^{1 / 2} D_{n} \mathrm{~ms}^{-2} \mathrm{~d}$

where $\operatorname{dose}_{n}$ was the total dose for the $n$th period; $a_{i}$ was the frequency weighted accleleration for the $i$ th tool; $t_{i}$ was the proportion of an 8 hour day in which the $i$ th tool was used; $D_{n}$ was the number of working days in the $n$th time period.

Lifetime dose $=\sum_{n}\left(\right.$ dose $\left._{n}\right) \mathrm{ms}^{-2} \mathrm{~d}$

ANALYSIS

The two exposure measures-lifetime hours of tool use and lifetime vibration dose-were categorised into tertiles. Prevalence ratios and 
Table 1 Age profile and estimated years of employment in use of vibrating tools (with comparative information from an earlier survey ${ }^{7}$ )

\begin{tabular}{|c|c|c|c|c|}
\hline & \multicolumn{2}{|c|}{$\begin{array}{l}\text { Current } \\
\text { sample }\end{array}$} & \multicolumn{2}{|c|}{1985 Survey* } \\
\hline Age $(y$, mean $(S D))$ & \multicolumn{2}{|c|}{$39.8(9.4)$} & \multicolumn{2}{|c|}{$36.3(-)$} \\
\hline$\leqslant 29$ & 21 & (13.8) & 336 & (38.5) \\
\hline $30-39$ & 53 & (34.6) & 239 & (26.7) \\
\hline $40-49$ & 54 & (35.3) & 138 & (15.4) \\
\hline$>50$ & 25 & (16.4) & 182 & (20.6) \\
\hline \\
\hline $\begin{array}{l}(\mathrm{y}, \text { mean }(\mathrm{SD})) \\
\mathrm{n}(\%) \text { : }\end{array}$ & \multicolumn{3}{|c|}{$16.1(7.7)$} & $(-)$ \\
\hline$\leqslant 10$ & 36 & $(23.6)$ & $325+$ & $(63.8)$ \\
\hline$>10-15$ & 24 & (15.7) & $70 \dagger$ & (13.7) \\
\hline$>15-20$ & 51 & (33.3) & $41 \dagger$ & $(8.1)$ \\
\hline$>20$ & 42 & (27.4) & $73+$ & (14.3) \\
\hline
\end{tabular}

*Walker et al.

tAltogether 386 exclusions because of: tool use $<1$ y, age $<20$, or previous tool use in former employment.

Table 2 Comparison of the weekly use of the compressor gun, rock drill, and wacker by distribution operatives in 1975, 1985, and 1994

\begin{tabular}{|c|c|c|c|}
\hline & $\begin{array}{l}1975 \\
(n=29)\end{array}$ & $\begin{array}{l}1985 \\
(n=102)\end{array}$ & $\begin{array}{l}1994 \\
(n=153)\end{array}$ \\
\hline \multicolumn{4}{|l|}{ Compressor gun: } \\
\hline $\begin{array}{l}\text { Mean (SD) } \\
\text { h/week }\end{array}$ & $15.6(6.2)$ & $12.4(7.7)$ & $5.5(4.7)$ \\
\hline$\%>15 \mathrm{~h} /$ week & 45 & 35 & 4 \\
\hline Rock drill: & & & \\
\hline $\begin{array}{l}\text { Mean (SD) } \\
\mathrm{h} / \text { week }\end{array}$ & $2.5(2.6)$ & $2.6(3.7)$ & $1.2(2.1)$ \\
\hline$\%>5 \mathrm{~h} /$ week & 14 & 14 & 3 \\
\hline Wacker: & & & \\
\hline $\begin{array}{l}\text { Mean (SD) } \\
\text { h/week }\end{array}$ & $5.6(5.2)$ & $5.9(5.4)$ & $3.4(4.6)$ \\
\hline$\%>10 \mathrm{~h} /$ week & 14 & 14 & 6 \\
\hline
\end{tabular}

95\% confidence intervals (95\% CIs) were derived for the three main outcomes, blanching, neurological complaint, and HAVS (blanching or neuorological complaint or both). The method used was generalised linear modelling in the packages STATA and GLIM with a binomial error and logarithmic link function with the methods described by Zocchetti et $a l^{11}$ and Wacholder, ${ }^{12}$ with necessary adjustments for confounding factors. Tests for trend were also performed across the exposure categories.

\section{Results}

STUDY POPULATIONS AND EXPOSURE ESTIMATES One hundred and fifty three distribution operatives took part in the study (response rate $81 \%$ ). Table 1 details the age profile of participants and their years of employment with vibrating tools. Comparative information from the 1985 gas industry survey is also given. ${ }^{7}$ The current study population represented a more work seasoned sample, including a greater proportion of long term tool users $(60 \%$ had used vibrating tools for $>15$ years, compared with $22 \%$ of those surveyed in 1985).

Our data indicate a change in the use of tools over time. Table 2 presents mean weekly exposure times to the main tool types in users who were also employed in 1975, $(n=29)$, in 1985 $(n=102)$, and in $1994(n=153)$. These suggest constant, relatively high weekly exposure times before 1985, but fewer tool hours a week more recently (on average one third fewer for the wacker than two decades ago, and two thirds fewer for the compressor gun). The findings reflect the success of no dig technology in curtailing workers' exposure to vibration.

\section{COMPLAINTS}

Nearly half of those surveyed (49\%) had one of the outcome measures, and often several in combination. According to our criteria, 38 men were counted as white finger cases. Thirty six of these had symptoms of blanching, among whom 13 had additional neurological complaints and definite or likely blanching on cold challenge; 20 had additional neurological symptoms but a negative cold challenge test, and three had a history of blanching in isolation. Two others (one with sensory symptoms) were counted as cases in the absence of a history of blanching because definite evidence of blanching was found on cold challenge. Thirty seven other workers had neurological complaints in isolation.

In two men from the blanching group and one from the neurological group the onset of symptoms preceded occupational exposure. If these men were excluded, the prevalence estimates were $24 \%$ for blanching and $46 \%$ for neurological complaints. In $18 \%$ of workers, neurological symptoms extended beyond the fingers into the hands, wrist, and arm; the distribution in nine men $(5.9 \%)$ was indicative of carpal tunnel syndrome and in six others $(3.9 \%)$ consistent with ulnar nerve entrapment.

In the analysis of prevalence ratios, adjustments were made for age (three bands) and depot (three groups), as these were related both to health outcomes and to exposures. History of connective tissue illness, and previous injury (to the hand, wrist, or fingers) were also explored as potential confounders, but were not associated with the health outcomes and were not considered further. Table 3 presents

Table 3 Prevalence of symptom complaints overall, and by estimated lifetime hours of use of vibrating tools and by lifetime dose of vibration

\begin{tabular}{|c|c|c|c|c|c|c|c|c|c|c|c|c|c|c|}
\hline \multirow[b]{3}{*}{ Symptom category } & & & \multicolumn{6}{|c|}{ Lifetime use of tools $(h)$} & \multicolumn{6}{|c|}{ Lifetime dose of vibration $\left(\mathrm{ms}^{-2} \mathrm{~d}\right)$} \\
\hline & \multicolumn{2}{|c|}{$\begin{array}{l}\text { All } \\
(n=153)\end{array}$} & \multicolumn{2}{|c|}{$\begin{array}{l}\leqslant 5000 \\
(n=49)\end{array}$} & \multicolumn{2}{|c|}{$\begin{array}{l}-15000 \\
(n=53)\end{array}$} & \multicolumn{2}{|c|}{$\begin{array}{l}>15000 \\
(n=51)\end{array}$} & \multicolumn{2}{|c|}{$\begin{array}{l}\leqslant 26500 \\
(n=50)\end{array}$} & \multicolumn{2}{|c|}{$\begin{array}{l}26500-47000 \\
(n=53)\end{array}$} & \multicolumn{2}{|c|}{$\begin{array}{l}>47000 \\
(n=50)\end{array}$} \\
\hline & $n$ & $\%$ & $n$ & $\%$ & $n$ & $\%$ & $n$ & $\%$ & $n$ & $\%$ & $n$ & $\%$ & $n$ & $\%$ \\
\hline No symptoms & 78 & $(51.0)$ & 37 & $(75.5)$ & 25 & $(47.2)$ & 16 & $(31.4)$ & 40 & $(80.0)$ & 19 & $(35.8)$ & 19 & $(38.0)$ \\
\hline Any HAVS symptoms* & 75 & $(49.0)$ & 12 & $(24.5)$ & 28 & $(52.8)$ & 35 & $(68.6)$ & 10 & $(20.0)$ & 34 & $(64.2)$ & 31 & $(62.0)$ \\
\hline Blanching $\dagger$ & 38 & $(24.8)$ & 3 & $(6.1)$ & 12 & $(22.6)$ & 23 & $(45.1)$ & 2 & $(4.0)$ & 16 & $(30.2)$ & 20 & $(40.0)$ \\
\hline Neurological (all) & 71 & $(46.4)$ & 12 & $(24.5)$ & 28 & $(52.8)$ & 31 & $(60.8)$ & 10 & $(20.0)$ & 33 & $(62.3)$ & 28 & $(56.0)$ \\
\hline Affecting hand or arm & 27 & $(17.6)$ & 3 & $(6.1)$ & 8 & $(15.1)$ & 16 & $(31.4)$ & 3 & $(6.0)$ & 9 & $(17.0)$ & 15 & $(30.0)$ \\
\hline Median nerve pattern & 9 & $(5.9)$ & 1 & $(2.0)$ & 5 & $(9.4)$ & 3 & $(5.9)$ & 1 & $(2.0)$ & 5 & $(9.4)$ & 3 & $(6.0)$ \\
\hline Ulnar nerve pattern & 6 & $(3.9)$ & 0 & $(0.0)$ & 3 & $(5.7)$ & 3 & $(5.9)$ & 1 & $(2.0)$ & 2 & (3.8) & 3 & $(6.0)$ \\
\hline
\end{tabular}

^Blanching or neurological symptoms or both.

†Symptoms or signs on cold challenge or both. 
Table 4 Adjusted ${ }^{\star}$ prevalence ratios and 95\% CIs for HAVS symptoms for different levels of lifetime hours of use of tools and lifetime dose of vibration

\begin{tabular}{|c|c|c|c|}
\hline Symptom and exposure & Prevalence ratio & $95 \% C I$ & $\begin{array}{l}p \text { Value for } \\
\text { trend }\end{array}$ \\
\hline \multicolumn{4}{|l|}{ HAVS: } \\
\hline \multicolumn{4}{|c|}{ Lifetime use of tools (h) } \\
\hline$\leqslant 5000$ & 1.0 & & \\
\hline $5000-15000$ & 1.7 & 1.0 to 2.9 & \\
\hline$>15000$ & 1.9 & 1.1 to 3.3 & $\mathrm{p}<0.02$ \\
\hline \multicolumn{4}{|c|}{ Lifetime dose of vibration $\left(\mathrm{ms}^{-2} \mathrm{~d}\right)$} \\
\hline$\leqslant 26500$ & 1.0 & & \\
\hline $26500-47000$ & 2.6 & 1.4 to 4.8 & \\
\hline$>47000$ & 2.3 & 1.2 to 4.3 & $\mathrm{p}<0.04$ \\
\hline \multicolumn{4}{|l|}{ Blanching: } \\
\hline \multicolumn{4}{|c|}{ Lifetime use of tools $(\mathrm{h})$ : } \\
\hline$\leqslant 5000$ & 1.0 & & \\
\hline $5000-15000$ & 2.5 & 0.8 to 8.1 & \\
\hline$>15000$ & 3.5 & 1.1 to 10.8 & $\mathrm{p}<0.01$ \\
\hline \multicolumn{4}{|c|}{ Lifetime dose of vibration $\left(\mathrm{ms}^{-2} \mathrm{~d}\right)$ : } \\
\hline$\leqslant 36000$ & 1.0 & & \\
\hline$>36000$ & 2.2 & 1.1 to 4.2 & \\
\hline \multicolumn{4}{|l|}{ Neurological symptoms: } \\
\hline \multicolumn{4}{|c|}{ Lifetime use of tools (h): } \\
\hline$\leqslant 5000$ & 1.0 & & \\
\hline $5000-15000$ & 1.7 & 1.0 to 2.9 & \\
\hline$>15000$ & 1.9 & 1.1 to 3.2 & $\mathrm{p}<0.03$ \\
\hline \multicolumn{4}{|c|}{ Lifetime dose of vibration $\left(\mathrm{ms}^{-2} \mathrm{~d}\right)$ : } \\
\hline$\leqslant 26500$ & 1.0 & & \\
\hline $26500-47000$ & 2.6 & 1.4 to 4.8 & \\
\hline$>47000$ & 2.2 & 1.2 to 4.2 & 0.05 \\
\hline
\end{tabular}

$\star$ Prevalence ratios have been adjusted for age in three bands $(<35,35-45,>45 \mathrm{y})$ and depot.

the numbers and percentages in each exposure outcome category and Table 4 presents the adjusted prevalence ratios and their 95\% CIs. (For the analysis of blanching there were only two cases in the baseline tertile for lifetime dose, and the resulting estimates proved unstable; in this analysis the median value was adopted as a cut off to create a dichotomous exposure variable).

The prevalences and prevalence ratios for HAVS, blanching, and neurological complaint rose significantly with estimated cumulative exposure, whether assessed in terms of lifetime hours of use of tools or lifetime dose of vibration. However, the trend was more apparent when lifetime hours were used as the basis for exposure estimation, and for the outcome of blanching rather than neurological complaint. The prevalence ratios for highest versus lowest tertiles of exposure assessed in lifetime hours were: $1.9(95 \% \mathrm{CI} 1.1$ to 3.3$)$ for HAVS, 3.5 (95\% CI 1.1 to 10.8 ) for blanching, and 1.9 (95\% CI 1.1 to 3.2) for neurological complaints. The respective figures for lifetime dose were: 2.3 (95\% CI 1.2 to 4.3 ) for HAVS, and 2.2 (95\% CI 1.2 to 4.2 ) for neurological complaint; for blanching, for which two exposure categories were defined, the prevalence ratio was 2.2 (95\% CI 1.1 to 4.2 ). The $\mathrm{p}$ value for trend was $\leqslant 0.05$ in all three band exposure comparisons.

OTHER OBSERVATIONS

Several other observations were made on the pattern, severity, and time course of complaints. The mean (SD) exposure interval to blanching among the 34 cases whose symptoms appeared after use of tools was 13.3 (7.2) years; most $(70 \%)$ had a Griffin score of $\leqslant 9$. Thus, blanching symptoms were generally mild and apparent only after prolonged exposure. There were exceptions, however: in seven cases the Griffin score was $>20$ and in 12 cases blanching developed in the first decade of employment. In eight cases symptoms had appeared between 1991 and 1994, over a period of markedly lower exposures.

In 18 men abnormal neurological signs (principally sensory loss) were recorded on clinical examination. No attempt was made to grade the severity of neurological complaints, or to measure them objectively, but when questioned, no affected man considered himself to have a work or leisure handicap. In 17 cases neurological complaints had first appeared between 1991 and 1994 .

Although the study did not examine musculoskeletal disorders in detail, a question was posed about troublesome symptoms in the upper limb. Elbow complaints were noteworthy both for their frequency and severity. Over the previous year, 38 workers $(25 \%)$ had experienced persistent pain or stiffness: 15 (9.8\% of all respondents) had been told by their doctor that they had lateral epicondylitis and eight $(5.2 \%)$ had received steroid injections. Two long serving workers had developed osteoarthritis of the elbow with fixed flexion deformity after use of vibratory tools. Elbow complaints were more common in the high exposure subgroups, but the adjusted prevalence ratios were not significantly increased (the prevalence ratios for highest versus lowest lifetime hours and lifetime dose categories were: 1.1 (95\%CI 0.5 to 2.2$)$ and 1.9 (95\% CI 0.8 to 4.7 ) respectively).

Five participants volunteered a history of vibration induced urticaria. This phenomenon has been noted before, ${ }^{13}{ }^{14}$ although rarely, and no systematic information was collected on it.

\section{Discussion}

The study methods have some potential limitations. Our estimates of exposure, in common with other cross sectional surveys of vibration and health, share the disadvantage of reliance on worker recall. In this respect the tool picture album proved a useful aid, and enabled a more detailed exposure history to be recorded than otherwise would have occurred. Workers' memories of the years in which particular tools were used generally agreed with company records; and our estimate of their mean exposure to the compressor gun in the 1980 s matched that of an earlier survey in the industry ${ }^{7}(12.5 v 12.4$ hours a week), providing some evidence of consistent exposure reporting. Exposure estimation can also be hampered if workers remember time spent on the job rather than the briefer interval of hand tool contact time. We placed emphasis on this distinction in history taking, but may not have avoided the problem entirely: company estimates of the running times of compressor generators in this period (although not available for inspection), were thought to imply briefer weekly exposure times. However, the method we used to estimate exposures is broadly comparable with those used elsewhere ${ }^{15}$ and in the health studies that underpin proposed control standards. Our data indicate a better doseresponse relation for estimated lifetime hours of exposure than for estimated lifetime vibratory dose, but the best method of estimating dose is not clear at present, ${ }^{17}$ and again our findings accord with those of others. ${ }^{18}$ 
The overall response rate of $81 \%$ provides some scope for recruitment bias. Men with symptoms may have been more likely to come forward than others. However, even if all nonparticipants were asymptomatic, the prevalence estimates of VWF and neurological complaints would still be high $(20 \%$ and $40 \%$ respectively).

In cross sectional surveys selection forces often operate to remove affected workers from the observation frame, as they leave employment. In our study seven former tool users requested an assessment, five of whom had histories of blanching; we also learned of several other workers who had been relocated because of health concerns. We have no information on the size and importance of these selection effects, but their direction would favour an underestimation of the health risk.

The case definition was based on clinical history and examination, rather than objective tests of dysfunction. But, to minimise false positive responses, emphasis was placed in case definition on demarcation of colour change and a minimum duration of response, as proposed by Gemne et al. ${ }^{19}$ Reliance on clinical history poses other difficulties in data classification: people may be reluctant to declare a health problem perceived to threaten job security (as may have occurred in the two workers who had signs of blanching on cold challenge but no declared symptoms); or they may be tempted to invent or exaggerate symptoms for motives of personal gain. In our survey, symptoms were generally at the mild end of the spectrum; less publicised complaints of a neurological nature were more common than the better known condition of blanching; and the histories of men were underpinned by observed blanching in almost half the cases, suggesting that if this problem occurred it was probably not a substantial source of bias. It is also possible to confuse coincidental primary disease in a tool user with secondary disease, but the pattern of disease in our sample argued strongly for secondary causation: more than half of those declaring blanching first developed symptoms after the age of 40 ; more than three quarters had asymmetric disease; only one man had a history of nose and toe involvement (against $40 \%$ in some reports of primary disease $^{20}$ ); and only one had a family history (in a brother who was also occupationally exposed). Finally, community studies in men in Hampshire, London, Merseyside, and Cheshire place the background prevalence of Raynaud's phenomenon at $5 \%-11 \%,{ }^{21}{ }^{22}$ much lower than the estimate in our population. There is less information on the community frequency of upper limb neurological symptoms, but our estimate sits comfortably within the range for workers exposed to vibration from other industries $(30 \%-80 \%){ }^{23}{ }^{24}$ Our prevalence estimate for carpal tunnel syndrome $(5.9 \%)$ is also higher than expected from population data $(0.6 \%)$, but close to that reported in high force high repetition jobs. ${ }^{25}$

Our findings differ from those of an earlier published survey in the gas supply industry, ${ }^{7}$ although a similar diagnostic questionnaire and method were used. The difference may well lie in the contrasting exposure histories of the two groups, and the higher proportion of long term tool users in our sample. Symptoms of blanching and neurological complaint were fairly common. They were generally mild and developed after considerable exposure, but there were exceptions, and cases had developed in recent times despite improved work conditions and lower exposures. Such cases may have arisen in workers who carry the legacy of prolonged early career exposures, and for whom the exposure pattern is fairly described as falling daily exposures, but high lifetime exposure and rising years of employment in tool use. Their vulnerability to current working conditions cannot be measured in a cross sectional survey, but argues for a cautious approach, and for health surveillance to monitor workers' wellbeing.

Our sample also had an excess of elbow complaints. We did not examine these, but an excess risk of lateral epicodylitis has been described in another survey of gas supply workers. ${ }^{26}$ In our survey, workers were often treated by injection or physiotherapy, suggesting an important degree of morbidity, although the neccessity of pain relief in a manual job may have prompted self referral in some cases. Distribution workers have to dig narrow trenches in confined spaces, and to exert considerable force in pushing narrow bore pipes through larger ones. It is not clear whether elbow complaints arise because of exposure to vibration, or from these manual aspects of the work, but further research is merited.

The formulation of risk assessment in the gas supply industry has been influenced by earlier work that described a low risk of blanching in distribution workers. It has been suggested that fundamental differences in work exposures such as the lower frequency spectrum of vibration mitigate against the risk of blanching that would normally be anticipated. Our data suggest that this special case argument may be too optimistic: symptoms of white finger do occur, as do other components of HAVS, given sufficient exposure. These findings are of direct relevance to workers from other industries who break and repair road surfaces, and are liable to face similar risks.

We thank the medical and secretarial staff of the Health and Safety Executive's Area South Office for their assistance in data collation and Dr Chris Nelson for his helpful advice on methods of exposure assessment. This work was undertaken in 1994 with the kind support of British Gas PLC, before its reorganisation.

1 Griffin MJ. Handbook of human vibration. London: Academic Press, 1990. (Appendix 8.)

2 Taylor W, Wasserman D, Behrens V, et al. Effect of the air hammer on the hands of stone cutters. The limestone quarries of Bedford, Indiana revisited. Br f Ind Med 1984; 41:289-95.

3 Hanley P. Specialist Inspectors report 44. Vibration hazards from road breakers. Sheffield: Health and Safety Executive, 1994.

4 Hempstock IJ, O'Connor DE. Evaluation of human exposure to hand-transmitted vibration. In: Proceedings of the International Occupational Hand-arm Vibration Conference, Cincinnati 1975. Cincinnati: US Department of Health, Education and Welfare, 1977:129-35.

5 Takamatsu M, Futatsukam, Sakurai T, et al. A study of the extent and scope of local vibration hazards in Japan. Ind Health 1982;20:177-90.

6 Christ E, Brush P, Donati P, et al for the International Section Research: Institute Nationale de Recherce et de Securite (INRS). Vibration at work. Paris: INRS, 1989. 
7 Walker DD, Jones B, Ogston S, et al. A study of white finger in the gas industry. Br F Ind Med 1985;42:672-7.

8 Walker DD, Jont B on S. Occurrence Walker DD, Jones B, Ogston S. Occurrence of white fing in the gas industry. Scand $\mathcal{f}$ Work Environ Health $1986 ; 4: 301-3$

9 Faculty of Occupational Medicine of the Royal College of Physicians. Hand-transmitted vibration: clinical effects and pathophysiology, part 1: report of a working party. London: RCP, 1993. (Appendix A2.)

10 Griffin MJ. Handbook of human vibration. London: Academic Press, 1990:573-5.

11 Zocchetti C, Consonni D, Bertazzi PA. Estimation of prevalence ratios from cross sectional data. Int $\mathcal{F}$ Epidemiol 1995; 24:1064-5.

12 Wacholder S. Binomial regression in GLIM: estimating risk ratios and risk differences. Am F Epidemiol 1986;123:17484 .

13 Wenef $\mathrm{MH}$, Metzger MD, Ronald A, et al. Occupationally acquired vibratory angioedema with secondary carpal tunnel syndrome. Ann Intern Med 1983;98:44-6.

14 Black AK. Mechanical trauma and urticaria. Am f Ind Med 1985;8:297-303.

15 Bovenzi $M$. Hand-arm vibration syndrome and doseresponse relation for vibration induced white-finger among quarry drillers and stonecarvers. Occup Environ Med 1994 51:603-11

16 Bovenzi M, Franzinelli R, Mancini R, et al. Dose-response relation for vascular disorders induced by vibration in the fingers of forestry workers. Occup Environ Med 1995;52: $722-30$.

17 Griffin MJ. Measurement, evaluation, and assessment of occupational exposures to hand-transmitted vibration. Occup Environ Med 1997;54:73-89.
18 Nelson CM, Griffin MJ. Comparison of predictive models for vibration-induced white finger. In: Dupuis $\mathrm{H}$, Christ E, Sandover J, et al, eds. Proceedings of the 6th International Conference on Hand-Arm Vibration. Bonn 1992. Sankt Augustin: HVBG, 1993:613-23. (HVBG, D-53754).

19 Gemne G, Pyykko I, Taylor W, et al. The Stockholm workshop scale for the classification of cold-induced Raynaud's phenomenon in the hand-arm vibration syndrome (revision of the Taylor Pelmear scale). Scand 7 Work Environ Health 1987;13:275-8.

20 Coffman JD. Raynaud's phenomenon. London: Oxford University Press, 1989:186.

21 Heslop J, Coggon D, Acheson ED. The prevalence of intermittent digital ischaemia (Raynaud's phenomenon, in a general practice. Fournal of the Royal College of General Practitioners 1983;33:85-9.

22 Silman A, Holligans, Brenman $\mathrm{P}$, et al. Prevalence of Raynaud's phenomenon in general practice. BMF 1990; 301:590-2.

23 Alaranta H, Seppalainen AM. Neuropathy and the automatic analysis of electro myographic signals from vibrationexposed workers. Scand 7 Work Environ Health 1977;3:12834 .

24 Matsumoto K, Itoh N, Kasamatsu $\mathrm{T}$, et al. A study of subjective symptoms based on total operating time of chain saw. Fapan fournal of Industrial Health 1977;19:22-8.

25 Silverstein BA, Fine LJ, Armstrong TJ. Occupational factors and carpal tunnel syndrome. Am F Ind Med 1987;11:34358

26 Ritz BR. Humeral epicondylitis among gas- and water-work employees. Scand f Work Environ Health 1997;21:478-86.

\section{Occupational and Environmental Medicine - http://www.occenvmed.com}

Visitors to the world wide web can now access Occupational and Environmental Medicine either through the BMJ Publishing Group's home page (http://www.bmjpg.com) or directly by using its individual URL (http://www.occenvmed.com). There they will find the following:

- Current contents list for the journal

- Contents lists of previous issues

- Members of the editorial board

- Subscribers' information

- Instructions for authors

- Details of reprint services.

A hotlink gives access to:

- BMJ Publishing Group home page

- British Medical Association website

- Online books catalogue

- BMJ Publishing Group books.

The web site is at a preliminary stage and there are plans to develop it into a more sophisticated site. Suggestions from visitors about features they would like to see are welcomed. They can be left via the opening page of the BMJ Publishing Group site or, alternatively, via the journal page, through "about this site". 